Dossiê

\title{
Diversidade cultural, território e tradição: a nova agenda do desenvolvimento local no Brasil
}

Elder P. Maia Alves'

Resumo: Diversos são os usos e agenciamentos exercidos sobre os territórios e seus lugares. O núcleo desses interesses repousa sobre as potencialidades simbólico-econômicas dos produtos e artefatos que materializam a diversidade cultural e as tradições histórico-culturais dos lugares. Não obstante, a valorização dos saberes locais e suas materialidades são seria possível sem a execução de determinadas políticas de desenvolvimento local, como as Indicações Geográficas (IGs), capitaneadas por agentes estatais de mercado, como o SEBRAE. São esses agentes que têm delineado a nova agenda do desenvolvimento local no Brasil.

Palavras-chave: Diversidade cultural; desenvolvimento local; tradições histórico-culturais; indicações geográficas; agenciamentos.

Cultural diversity, territory and tradition: the new agenda of local development in Brazil.

Abstract: There are several uses and assemblages exercised over the territories and their places. The core of these interests rests on the symbolic and economic potential of products and artifacts that embody the cultural diversity and the historical

1 Programa de Pós-Graduação em Sociologia - Universidade Federal de Alagoas (UFAL) - Maceió - Brasil epmaia@hotmail.com. 
and cultural traditions of the places. Nevertheless, the use of local knowledge and its material issues are possible without the implementation of specific local development policies, such as geographical indications (GIs), captained by market-state actors, as SEBRAE. These are agents that have outlined the new agenda of local development in Brazil.

Keywords: Cultural diversity; local development; historical and cultural traditions; geographical indications; assemblages.

\section{Introdução}

Inúmeras são as localidades, os territórios e as regiões brasileiras e globais que, nos últimos vinte anos, lançaram mão de tecnologias, políticas culturais, políticas de desenvolvimento regional e da criação de arranjos organizacionais para valorizar os imaginários, as tradições, as criações culturais, os aspectos naturais, as expressões e as narrativas indenitárias de determinados lugares e territórios. No Brasil, especialmente nos últimos dez anos, diferentes políticas, formuladas e executadas por distintos agentes estatais e governamentais, como o Ministério da Cultura, o Ministério do Desenvolvimento, Indústria e Comércio, o Serviço de Apoio à Micro e Pequenas Empresa (SEBRAE) e o Instituto Nacional de Propriedade Industrial (INPI), construíram afinidades eletivas que aproximam e justapõem as categorias-valor de diversidade cultural, identidade, tradição, criatividade, inovação, empreendedorismo, território e desenvolvimento. É um dos desafios deste trabalho evidenciar como essas categorias/ valor se aproximaram, alinhavando uma nova rede de justificação que criou as condições para a estruturação dos negócios da diversidade/identidade nos e dos territórios. Tais negócios estão ancorados fundamentalmente no valor de autenticidade que os consumidores reputam a determinadas expressões, rituais, festas, celebrações, alimentos, bebidas, artesanatos, utensílios, joias, objetos etc. O valor da autenticidade é resultado de uma negociação complexa, que decorre das formas de retenção de poder simbólico e cultural realizado por variados grupos de interesse. Todavia, são as demandas de consumo por novas sensações, emoções, vibrações, fantasias, autoexpressão, autorealização e experiências "autênticas" (Bauman, 2008: 121; Taylor, 2011: 21; Lipovetsky, 2015: 41; Canclini, 2013: 63), que dinamizam os negócios da "autenticidade".

Um dos dispositivos legais que potencializa diretamente o valor de autenticidade/tradição das criações histórico-culturais dos territórios é a Indicação Geográfica (IG). Única modalidade de propriedade intelectual de uso coletivo 
no âmbito da propriedade intelectual global, a Indicação Geográfica protege os direitos do uso comercial, publicitário e simbólico dos produtos e serviços consagrados como originários e procedentes do processo de formação histórico, cultural e natural de determinados lugares e territórios. As Indicações Geográficas (IGs) são utilizadas como recurso jurídico, econômico e simbólico pelos detentores coletivos desse direito, invariavelmente formados por associações, cooperativas e sindicatos. Os usos variados e os agenciamentos simbólico-econômicos das IGs, no entanto, geram ativos que dinamizam os negócios de uma intrincada e assimétrica rede de empresas (pequenas, médias e grandes), que fomentam postos muito específicos de trabalho, emprego e renda.

O reconhecimento das Indicações Geográficas brasileiras é feito pelo Instituto Nacional de Propriedade Industrial (INPI), ligado ao Ministério do Desenvolvimento, Indústria e Comércio (MDIC); decorre de um longo e complexo processo de estudos técnicos, mobilização de competências científicas, engajamentos políticos, interesses econômicos e alianças interinstitucionais por parte de diferentes agentes estatais, governamentais, empresariais, associativos e comunitários.

Estamos diante de uma nova agenda político-econômica que tem duas frentes empíricas bastante recentes. De um lado, as principais metodologias e mecanismos de governança utilizados para a elaboração das políticas de desenvolvimento local (como a criação dos arranjos produtivos locais, APLs, e a incubação de empresas) cada vez mais incorporam a justificativa da cultura como alavanca para o desenvolvimento; de outro lado, os principais agentes político-institucionais implicados nessas governanças passam a adotar programas e projetos voltados à inclusão produtiva, ao empreendedorismo criativo, ao aprimoramento da competitividade e inovação tendo em conta a oferta de produtos histórico-culturais que dinamizam o fluxo turístico e os negócios vinculados à diversidade cultural e à valorização das identidades locais. A primeira frente será explorada na primeira parte deste trabalho; já a segunda será objeto da seção seguinte, onde a ênfase recairá sobre o caso da Indicação Geográfica do bordado Filé, do Estado de Alagoas.

Diversidade, identidade e produto: 0 território como novo ativo simbólico-econômico - a atuação dos agentes estatais de mercado (AEM).

No centro da nova agenda político-econômica que cria as condições práticas para a profusão das Indicações Geográficas (IG), das incubadoras de empresas culturais e dos arranjos produtivos locais (APLs) intensivos em cultura, estão os agentes estatais de mercado (AEM). São esses os responsáveis pela elaboração 
de uma nova e densa teia discursiva, capaz de instaurar um novo regime de verdade (Foucault, 1988: 88). Os agentes estatais de mercado (AEM) correspondem aos órgãos governamentais dos três níveis político-administrativos, tanto da administração direta quanto indireta do poder executivo, assim como bancos públicos, fundações estaduais de pesquisa, empresas estatais (federais e estaduais), universidades (estaduais e federais), órgãos de estímulo ao empreendedorismo, entre outros.

Os AEM são instituições que, no Brasil e em diversas partes do globo, elaboram políticas, executam ações e mobilizam recursos imprescindíveis para a construção dos mais variados mercados. Assim como as empresas privadas e os consumidores, os agentes estatais de mercado (AEM) integram o núcleo dos principais mercados capitalistas globais. Além das infraestruturas públicas, das logísticas e dos empréstimos financeiros que dinamizam os mercados, bem como dos dispositivos legais de controle e regulação, em países como o Brasil as instituições estatais também são uma das principais responsáveis pela disseminação da ética empreendedora, pela transmissão da pedagogia da competitividade e pelos arranjos organizacionais/institucionais que estimulam a inovação.

Os agentes estatais de mercado (AEM) não substituem os agentes privados de mercado (as empresas privadas e as grandes corporações - nacionais e multinacionais), ao contrário, criam as condições econômicas e políticas para que os agentes privados de mercado (APM) se disseminem e cresçam e, assim, gerem trabalho, emprego e renda, mas, sobretudo, mercadorias, produtos e serviços, e, com isso, possam elevar os níveis financeiros de arrecadação tributária do próprio Estado. Os agentes estatais de mercado (AEM) não possuem a mesma racionalidade empresarial praticada pelos agentes privados de mercado, marcada pelo cumprimento de metas comerciais, estratégias de marketing e resultados financeiros definidos. No entanto, as políticas de estímulos ao empreendedorismo, à liberação de empréstimos financeiros para determinados setores, os incentivos à inovação e à profusão do discurso da competitividade, presente nas ações de muitas agências estatais, órgãos governamentais e fóruns políticos, reforça, consolida e atualiza parte dos conteúdos que integram as racionalidades empresariais praticadas pelas corporações privadas. Esse aspecto é tanto mais forte entre as micro e pequenas empresas.

As transformações político-conceituais envolvendo o binômio cultura e desenvolvimento explicam parte das mudanças envolvendo o advento de uma nova rede semântico-discursiva que sustenta e organiza a nova gramática do desenvolvimento local. Entre os anos 40 e 70 do século passado, os teóricos da modernização e as agências estatais de desenvolvimento regional, como a brasileira 
SUDENE (Superintendência de Desenvolvimento do Nordeste), foram informados pelos dois registros conceituais mais correntes da noção de cultura: a cultura como totalidade dos costumes, crença, hábitos, tradições e visões de mundo e a acultura como linguagem expressiva e manifestações simbólicas. Os dois registros se cruzavam e se retroalimentaram, plasmando a seguinte assertiva: as tradições histórico-culturais da periferia do capitalismo eram refratárias ao desenvolvimento. Ora, como as tradições histórico-culturais dos territórios se tornam uma poderosa justificativa para o desenvolvimento se até pouco tempo eram vistas como um dos grandes entraves para se alcançar esse mesmo desenvolvimento?

Os conceitos de cultura e desenvolvimento expandiram seus núcleos de significação, justificação e operacionalização político-econômica nas duas últimas décadas. $\mathrm{O}$ alargamento do conceito de cultura incorporou a noção de cultura como experiência vivida e saber informal acumulado, valorizando as noções de diversidade, identidade, memória, tradição, história e patrimônio imaterial. De outro lado, também passou a depositar grande ênfase na noção de cultura enquanto produção técnico-artística especializada, inserida nos mercados globais de circulação e fruição de bens e serviços culturais. Por seu turno, a noção desenvolvimento também sofreu um acentuado deslocamento. Seu conteúdo econômico foi atenuado, os antigos índices macroeconômicos foram revistos a partir de sua relação com as condições de vida das populações mais pobres. O desenvolvimento econômico-industrial passou a ser visto como uma das dimensões do desenvolvimento humano. Assim, no decurso das décadas de 1980 e 1990, as categorias de cultura e desenvolvimento se aproximaram e se interpenetraram, acomodando suas antigas antinomias. Em face das mudanças na noção de desenvolvimento, aquilo que, entre os anos de 1940 e 1970, era visto como um dos grandes obstáculos para se alcançar o desenvolvimento econômico-material, passou a constituir um dos substratos fundamentais do desenvolvimento, pois é reputada como a grande fonte da criatividade e potencial geradora da inclusão produtiva por meio da riqueza histórico-cultural e natural dos territórios.

Hoje se reconhece que quanto mais denso, diverso e rico o conteúdo cultural de uma sociedade, maiores as suas possibilidades de desenvolvimento. $\mathrm{O}$ vigor das manifestações culturais mais enraizadas permite sua preservação e difusão e pode representar uma significativa alternativa de inclusão produtiva (Coutinho, 2011: 22).

Trata-se de uma mudança bastante significativa o fato de o Banco Nacional de Desenvolvimento Econômico e Social (BNDES) positivar, hoje, o caráter das 
"manifestações culturais mais enraizadas", celebrando os atributos e as potencialidades de desenvolvimento diretamente vinculado ao maior grau de densidade, diversidade e riqueza cultural de uma sociedade, justamente os fatores que o receituário clássico do desenvolvimentismo julgava como obstáculos. Segundo o IBGE, entre 2006 e 2014 ocorreu um aumento expressivo dos municípios que possuem secretarias dedicadas exclusivamente ao tema da cultura. Em 2006, os municípios com secretarias exclusivas para a cultura correspondiam a 4,3\% do total, ao passo que em 2014 esse percentual saltou para 20,4\%. De acordo com o IBGE, em 2014, 14 estados brasileiros, do total de 27 (incluindo o Distrito Federal), informaram que, no âmbito das suas políticas culturais, um dos objetivos centrais era a integração da cultura ao desenvolvimento local. Na primeira pesquisa realizada pelo IBGE, em 2006, esse objetivo foi muito pouco citado e documentado. Já no âmbito dos 5572 municípios brasileiros, 32,5\% afirmaram que um dos principais objetivos das suas políticas culturais era integrar a cultura ao desenvolvimento local. Em 2006, esse percentual era de $27 \%$. Ainda mais relevante é o fato de que um acervo novo de ações e programas ligados ao desenvolvimento local, sustentabilidade e empreendedorismo criativo emergiu com bastante força no mesmo levantamento realizado pelo IBGE. De acordo com o instituto, em 2014, 18 Estados da Federação afirmaram desenvolver ações e programas específicos dirigidos à produção cultural local autossustentável; 15 salientaram que desenvolvem programas destinados à formação, capacitação e qualificação de competências criativas; 14 sustentaram que mantem programas de articulação e estímulo ao fomento de empreendimentos criativos e 12 informaram que mantêm ações regulares destinadas a criação, produção, circulação ou distribuição de bens e serviços criativos. No âmbito dos municípios, 26,9\% do total dos municípios brasileiros afirmaram que mantêm programas para a produção cultural local sustentável; 13,8\% informaram que desenvolvem ações permanentes de estímulo ao fomento de empreendimentos criativos e $13,4 \%$ sustentaram que executam ações de formação, capacitação e qualificação para as competências criativas (IBGE, 2015).

Especialmente por meio dos aspectos envolvendo cultura e desenvolvimento presentes no Plano Nacional de Cultura (PNC) e no Sistema Nacional de Cultura, o Ministério da Cultura (MINC) foi o principal responsável pela institucionalização da integração da cultura ao desenvolvimento local junto à administração cultural pública brasileira. Foi também o MINC o principal artífice do processo de institucionalização e legitimação dos programas direcionados à formação, capacitação e qualificação de competências criativas; às ações de estímulo ao fomento de empreendimentos criativos e aos programas de criação, produção, 
circulação ou distribuição de bens e serviços criativos locais. O tema da economia criativa, acompanhado da constatação de que a cultura - tanto no que se refere às tradições histórico-culturais, quanto no que diz respeito a geração de serviços, atividades e bens simbólicos - é um fator central do novo desenvolvimento regional, abriu uma nova frente de atuação para o Ministério da Cultura.

Desde 2003 o MINC passou a estabelecer parcerias institucionais com organizações que esposavam poucos interesses pelas atividades simbólico-culturais ou pelo tema da cultura de um modo geral. Passam a orbitar as ações e programas do MINC agentes como o IBGE, o IPEA (Instituto de Pesquisa Econômica Aplicada), o SEBRAE, o Ministério de Ciência, Tecnologia e Inovação (MCTI), o Ministério do Desenvolvimento, Indústria e Comércio Exterior (MDIC) e a Secretaria da Micro e Pequena Empresa (SMPE). Em 2013, o Ministério do Desenvolvimento, Indústria e Comércio Exterior (MDIC), em parceria com o MINC, divulgou o Chamamento Público n. 03/2013, destinado à seleção de 27 arranjos produtivos locais (APLs) intensivos em cultura, um em cada unidade da Federação. Um dos propósitos da parceria foi inserir os APLs intensivos em cultura no âmbito da nova Política Nacional de Desenvolvimento Regional (PNDR, 2011). Em 2014 foi criada a Rede Incubadora Brasil Criativo, parceria da SEC/MINC com alguns governos estaduais, entre eles Mato Grosso, Bahia, Pará, Acre, Minas Gerais, Goiás, Ceará, Rio de Janeiro, Rio Grande do Sul, Pernambuco e Distrito Federal. A meta central a ser alcançada seria a criação de centros estaduais de incubação de empresas culturais, que receberiam assessoria técnica de órgãos e empresas especializadas, financiadas pelos governos estaduais e o Ministério da Cultura (MINC).

Tanto a instalação dos APLs intensivos em cultura, quanto a criação dos centros estaduais de incubação de empresas culturais, derivam da força política e teórica que o conceito/tema de economia criativa/ indústrias criativas tem logrado no ambiente empresarial, governamental e acadêmico brasileiro. Diante do seu pendor normativo e pouco reflexivo, categorias como as de economia criativa não possuem estatuto propriamente analítico e explicativo, posto que condensa muito mais o resultado de lutas, disputas, agenciamentos e interesses políticos, corporativos e técnicos. O conceito de economia criativa é muito mais o resultado das interfaces e interesses envolvendo a produção intelectual de prestigiadas escolas de negócios globais, os objetivos econômicos de alguns governos nacionais e a atuação político-normativa de agências transnacionais, como a UNCTAD e UNESCO. Como corolário, trata-se de uma formulação nativa, cunhada, manejada, aplicada e legitimada por determinados agentes político-institucionais. 
Desse modo, importa tomar o conceito não como uma categoria analítica e explicativa, mas como uma categoria nativa (um meta-discurso) mobilizada por poderosos agentes econômico-culturais para justificar ações e legitimar novas estratégias e oportunidades de negócios. Interessa, pois, muito mais os usos práticos do conceito e as suas implicações político-econômicas e muito menos o eventual potencial explicativo e interpretativo que o conceito contém. Os dados extraídos do IBGE, constatando a institucionalização do temário e do léxico da economia criativa no interior da administração pública brasileira, demonstra a fecundidade metodológica de se operar por meio dessa perspectiva.

As parcerias do Ministério da Cultura junto aos órgãos mencionados anteriormente sedimentam uma face inteiramente nova do MINC: um ministério que também valoriza, difunde e estimula o empreendedorismo cultural. Essa face o torna um agente estatal de mercado (AEM) decisivo para a construção dos mercados culturais, especialmente para a consecução do valor da autenticidade. Esse aspecto se consolida ainda mais quando se põe em tela, por exemplo, a execução de programas de maior impacto econômico, como o Vale Cultura e o Fundo setorial do Audiovisual (FSA).

O primeiro, coordenado pela secretaria de Incentivo e Fomento à Cultura do MINC, é como primeiro grande programa de indução direta de formação de consumidores de bens culturais. Por meio da concessão de um vale destinado ao consumo de mais de 30 atividades, serviços e bens culturais, os trabalhadores que recebem até cinco salários mínimos recebem o valor de $\mathrm{R} \$ 50,00$ mensais destinado exclusivamente ao consumo de conteúdos culturais. $\mathrm{O}$ modelo foi inspirado na concessão dos vales transporte e alimentação, direto consagrado dos trabalhadores brasileiros. No caso do vale cultura, a empresa cadastrada arca com a maior parte do custo; o governo, por sua vez, concede às empresas que aderem ao programa descontos fiscais e tributários. O programa foi criado em 2013, até o fim de 2015 mais de mil empresas já haviam aderido ao programa, alcançando cerca de 500 mil trabalhadores detentores do vale, o que corresponde a um consumo de aproximadamente $\mathrm{R} \$ 200$ milhões (MINC, 2015). A expectativa do Ministério da Cultura é que, nos próximos dez anos, cerca de $\mathrm{R} \$ 15$ bilhões sejam injetados nos mercados culturais e suas cadeias de valor por conta do vale cultura. Já o Fundo Setorial do Audiovisual (FSA) evidencia ainda mais a condição do sistema MINC como um agente estatal de mercado específico. O FSA foi criado em 2001, quando da criação da Agencia nacional de Cinema (ANCINE), ligada ao Ministério da Cultura, mas, de fato, somente passou a impactar diretamente o mercado audiovisual a partir de 2011, com a aprovação e regulamentação da Lei 12.485 (nova lei da TV por assinatura). Essa 
lei estabeleceu que o CODECINE (contribuição tributária para o desenvolvimento da indústria cinematográfica brasileira) passasse a incidir sobre todos os serviços de telecomunicações e telefonia móvel. Como as principais operadoras de telefonia móvel passaram a atuar na TV por assinatura, e essa, por sua vez, logrou um avassalador crescimento da sua base de assinantes, saindo de pouco mais de 9 milhões de assinantes, em 2010, para quase 20 milhões de assinantes em 2014, a arrecadação do CODECINE saltou de pouco mais de $\mathrm{R} \$ 43$ milhões em 2010, para mais de $\mathrm{R} \$ 1$ bilhão em 2015. Com esses recursos, a ANCINE, por meio de convênio com o BNDES, criou diversas linhas de financiamento para as empresas que atuam na cadeia produtiva do audiovisual (produtoras, distribuidoras e exibidoras).

De acordo com o Tesouro Nacional, entre 2003 e 2014, os recursos orçamentários para a cultura (excluindo-se as leis de incentivo) cresceram aproximadamente $300 \%$. Mesmo descontando-se a inflação acumulada no período, $97 \%$ (IPCA), o crescimento se mantém bastante elevado. Essa elevação orçamentária se deveu, sobretudo, ao crescimento dos gastos realizados pela União. Em 2013 esse ente federativo respondia por apenas $10 \%$ da totalidade dos recursos destinados à administração cultural, ao passo que em 2014 alcançou o percentual de $20 \%$, algo em torno de R 1,76 bilhões. Embora o aumento do orçamento destinado às políticas culturais revele a consolidação de um domínio temático específico no interior do ordenamento estatal brasileiro, não é, todavia, esse o principal aspecto que faz do sistema MINC um agente estatal de mercado (AEM). O que o torna um AEM específico é o fato de que, hoje, o sistema federal de cultura tem elaborado e executado políticas que buscam dinamizar os negócios culturais, estimulando a criação e a expansão das empresas de cultura - sejam micro, pequenas, médias ou grandes.

A intensificação da globalização na última década do Século XX instilou a percepção de que o mundo estaria passando por um processo acelerado de homogeneização e padronização cultural. Foi em nome da defesa e da promoção da diversidade cultural que muitos governos, entidades da sociedade civil, associações de artistas, intelectuais e instituições transnacionais passaram a defender a elaboração de novas políticas de cultura. Essas mobilizações culminaram na aprovação da Convenção Sobre a Proteção e a Promoção da Diversidade das Expressões Culturais, em 2005, e a Convenção para Salvaguarda do Patrimônio Cultural Imateriais, em 2003, ambas sob os auspícios da UNESCO. Dificilmente os territórios teriam se convertido em ativos simbólico-econômicos sem a criação de uma rede de políticas destinadas a salvaguardar, valorizar e estimular a diversidade cultural e as tradições histórico-culturais dos lugares. 
Nesse caso, salta aos olhos a institucionalização da política do patrimônio imaterial no Brasil, especialmente as ações levadas a cabo pelo Programa Nacional do Patrimônio Imaterial (PNPI), conduzido pelo Centro Nacional de Folclore e Cultura Popular (CNFCP) e pelo Departamento de Patrimônio Imaterial (DPI), ambos diretamente ligados ao Instituto do Patrimônio Histórico e Artístico Nacional - IPHAN.

Criado em 2000, por meio do Decreto n. 3.551/oo, o PNPI consiste em criar ações com vistas à proteção e promoção do patrimônio cultural imaterial brasileiro. Informado por olhar conceitual que busca mitigar os aspectos físicos e arquitetônicos da noção de patrimônio, responsável pelo tombamento de diversos sítios históricos e arquitetônicos ao longo do Século XX, o programa contribuiu para difundir uma nova noção de patrimônio, que retira o seu substrato das formas de fazeres, saberes, modos de expressão e celebrações inscritas nas memórias, nas identidades, nas tradições e nas práticas populares. O núcleo central do programa corresponde ao processo de indicação e reconhecimento do registro/ título de Patrimônio Cultural Imaterial Brasileiro, que se ampara em um longo e complexo processo de pesquisa histórico-antropológico, que se inicia com a feitura de um dossiê e pode culminar com a concessão do registro. $O$ pedido de concessão do registro pode ser desencadeado por entidades da sociedade civil, pelos poderes públicos locais e estaduais, por meio dos grupos culturais e demais instituições interessadas.

Nos últimos 13 anos, 35 bens foram registrados como Patrimônio Cultural Imaterial Brasileiro. Desses, 16 estão situados na Região Nordeste; 9 na região Sudeste; 9 na região Norte e um na região Centro-Oeste. Do total, 3 também são Indicações Geográficas - as panelas de barro de Goiabeiras, ES; o queijo de Minas, da região do Serro e a Renda Irlandesa, do munícipio de Divina Pastora, SE. São expressões, festas, rituais, gêneros musicais, ofícios, práticas e lugares divididos em quatro livros de registro: Livro de Registro dos Saberes; Livro de Registro das Celebrações; Livro de Registro das Formas de Expressão; Livro de Registro dos Lugares. Embora a maioria dos bens envolva diversas materialidades (bolo de acarajé, panelas, queijo, sinos, tambores, praças, tecidos, entre tantos outros), o registro consiste em reconhecer a imaterialidade das práticas e o seu complexo de saberes, fazeres e expressões, resultado de um longo processo histórico-cultural de aprendizado informal e transmissão intergeracional das memórias coletivas.

Os 35 bens registrados como Patrimônio Cultural Imaterial Brasileiro se inscrevem na esfera conceitual daquilo que, até a década de 1980 do Século XX, era nomeado como cultura popular. Por sua vez, para muitos dos formuladores das 
políticas culturais, gestores e grupos de pressão, as culturas populares tradicionais constituem a fonte mais vibrante da diversidade cultural. De acordo com a MUNIC/IBGE, todos os estados brasileiros mantêm políticas específicas para o que a pesquisa designou como campo da diversidade cultural. O levantamento considerou as ações e programas para treze segmentos: culturas populares (realizadas em todos os estados); comunidades indígenas (implementadas em 20 estados); comunidades afro-religiosas (desenvolvidas por 20 estados); quilombolas (executadas por 19 estados); crianças e adolescentes (realizadas por 18 estados); jovens (executas em 18 estados); além de outras comunidades tradicionais. Já no âmbito dos municípios, o levantamento identificou que 53,9\% do total executam ações para as culturas populares.

O fundamento teórico-conceitual do Programa Nacional do Patrimônio Imaterial (PNPI) é fornecido pela antropologia cultural, especialmente a partir das noções de memória, imaterialidade, diversidade, tradição, comunidade, identidade, cultura popular, fazeres e saberes - categorias que ingressaram em novas arenas político-econômicas. $\mathrm{O}$ registro do patrimônio imaterial é uma conquista político-cultural dos portadores dos fazeres, dos saberes e das formas de expressão, são títulos que trazem reconhecimento e dignidade para os seus detentores, mas também se tornaram selos e marcas distintivas que potencializam a geração de valor simbólico-econômico. Como atesta a MUNIC/IBGE 2014, nos últimos dez anos as políticas para o patrimônio imaterial experimentaram um forte processo de institucionalização no Brasil. Em 2006, apenas 2,5\% dos municípios brasileiros possuíam políticas específicas para o patrimônio cultural imaterial, já em 2014 eram 11,6\%. No âmbito dos estados, em 201416 unidades da federação mantinham políticas dirigidas ao patrimônio imaterial; em 2006 eram apenas 7, com destaque para estados como a Bahia, que possui duas leis e um decreto de defesa e valorização do seu patrimônio imaterial; Ceará (três leis e um decreto), Pernambuco (uma lei e três decretos); e Rio de Janeiro (duas leis).

De acordo com o IBGE, a legislação de defesa do patrimônio material e imaterial também aumentou em todas as categorias de municípios, com destaque para aqueles situados na região Sudeste, que saíram de 39,2\%, em 2006, para 55,5\% em 2014. Tanto o patrimônio material quanto o imaterial estão umbilicalmente vinculados ao turismo cultural e seus negócios. O primeiro já abriga essa vinculação há bastante tempo, todavia, nos últimos dez anos as ações de recuperação e requalificação dos bens histórico-arquitetônicos tombados se intensificaram. Um exemplo é o programa PAC (Programa de Aceleração do Crescimento) das Cidades Históricas, que, desde 2013, conta com recursos da Caixa 
Econômica Federal (CEF), da ordem de $\mathrm{R} \$ 1,6$ bilhões, destinados à restauração e à recuperação de 425 edifícios e espaços públicos (IPHAN, 2014). Coube ao IPHAN conceber todo o projeto do PAC das Cidades Históricas, assim como coordenar a construção de uma rede de sinergias locais entre universidades, governos municipais, estaduais e entidades locais. Não é preciso assinalar que, nesse e em outros casos, órgãos estatais como o IPHAN, além de cumprirem as suas funções de regulação e disciplinamento, também atuam como agentes estatais de mercado (AEM), mesmo que esse não seja o propósito.

A escolha das cidades, dos equipamentos e, por conseguinte, a concessão dos recursos redunda em toda sorte de negócios que se criam no rastro do aumento das visitações e do crescimento do fluxo de turistas em consequência da ampliação da oferta de bens artístico-arquitetônicos nos sítios históricos. O percentual de municípios que passaram a implementar programas e ações voltados ao turismo cultural cresceu de 26,2\%, em 2006, para 61\%, em 2014 - crescimento de quase $250 \%$ (IBGE, 2014). Essa extensa rede de municípios intensificou as suas ações para a formação de guias e roteiros, para o fomento de festividades e eventos (feiras gastronômicas; mostras de cinema; festas literárias; festivais de música; eventos religiosos; feiras de artesanato, entre outros) e para a promoção de seus patrimônios materiais e imateriais. Estados e prefeituras criam as condições diretas para a profusão dos negócios turístico-culturais, dinamizando, entre outros aspectos, o processo de turistificação e culturalização dos territórios (Urry, 1996: 123). O que secunda a nossa hipótese de que os agentes estatais de mercado (AEM) são decisivos para a expansão dos mercados turísticos e culturais.

No que toca ao patrimônio cultural imaterial, a relação com o turismo cultural e os negócios dos e nos territórios é menos pronunciada, suas tramas de interdependência são mais sutis e sinuosas. Na maioria esmagadora dos casos, a solicitação inicial para a obtenção do registro/título de Patrimônio Cultural Imaterial Brasileiro não foi estimulada por uma razão utilitária econômica, longe disso. Tampouco o IPHAN e o seu Departamento de Patrimônio Imaterial (DPI) agem como agentes estatais de mercado, que buscam criar as condições para a profusão das empresas e seus empreendimentos. Ocorre que a concessão/ conquista do registro/título, que chancela uma imaterialidade específica, profundamente ligada à dinâmica cultural dos lugares e suas tradições, logo se torna um ativo econômico.

A construção desse ativo depende do grau de agenciamento e interesses dos agentes estatais de mercado locais (secretaria de cultura, fundações, secretarias de turismo, SEBRAEs etc.) e, sobretudo, dos agenciamentos e usos econômicos 
que as empresas locais (agências de viagens, redes de restaurantes, associações de comerciantes, hotéis, empresas de transporte etc.) fazem do registro/título de patrimônio imaterial. Logo, a defesa e valorização das tradições culturais locais, da sua diversidade, identidade e imaterialidade, traduzida em um selo/registro (patrimônio cultural imaterial), torna-se uma marca distintiva, um recurso simbólico que, conjugado a outros, corrobora para a construção da oferta dos destinos, lugares e territórios que podem oferecer o consumo do "genuíno", do "autêntico", do diverso e raro. São essas as categorias-força essencializadoras que os agentes (empresas, governos, grupos culturais e imprensa) utilizam para emprestar aos seus territórios e às suas identidades dignidade e reconhecimento.

Talvez o principal agente estatal de mercado (AEM) no Brasil seja o sistema SEBRAE. Criado em 1972, é uma entidade pertencente ao sistema S - designação das contribuições tributárias arrecadadas pela União e repassadas a onze entidades patronais, trabalhistas e corporativas. O SEBRAE tem sido um dos grandes responsáveis pela transmissão da pedagogia do empreendedorismo e da ética da competitividade no Brasil. A noção de empreendedorismo e o seu léxico correspondente constituem o núcleo de uma nova gramática corporativa e colaborativa que organiza as racionalidades empresariais, disseminadas, em maior ou menor grau, por redes, instituições, empresas, governos, regiões, territórios e cidades. Trata-se de um princípio prático, ideológico, discursivo e também uma ética mobilizadora que anima e orienta a pedagogia institucional do SEBRAE. No Brasil, a cada ano, são abertas 316 mil novas empresas. Dessas, aproximadamente $85 \%$ são micro e pequenos empreendimentos, que, em 2013, representavam $96 \%$ das empresas brasileiras e $26 \%$ do Produto Interno Bruto (PIB). De acordo com o Ministério do Trabalho e Emprego (MTE), existiam, em 2012, 6,3 milhões de estabelecimentos que figuravam como micro e pequenas empresas, responsáveis pelo estoque de 15,6 milhões de empregos formais privados não-agrícolas. Esses números posicionam o Brasil a frente de países como Alemanha, Índia e Itália. O SEBRAE é um dos principais artífices desse processo.

De acordo com o BNDES, em 2012, 94\% dos empregos criativos estavam concentrados nas micro e pequenas empresas. Não por acaso, o SEBRAE tem sido um dos principais agentes de disseminação e legitimação do conceito de economia criativa, do tema do empreendedorismo cultural e da justificação da promoção do desenvolvimento local por meio da cultura. Em 2015 o SEBRAE nacional lançou um volumoso guia explicativo-prático acerca da cadeia produtiva da música - Música tocando negócios: um guia para ajudar a você empreender na música. Direcionado para os profissionais e empresas que atuam no 
mercado musical, em pouco tempo o guia já se tornou uma importante referência didática e prática.

O SEBRAE nacional e os SEBRAEs estaduais, definem, manejam e aplicam o conceito/tema da economia criativa de acordo com os seus interesses institucionais e conveniências político-organizacionais. Por exemplo, à luz da sua atuação junto às micro e pequenas empresas, lançou, em 2012, um documento balizador, denominado Termo de Referência - Atuação do Sistema SEBRAE na Economia Criativa. Nele estabelece os seguintes eixos norteadores: 1) desenvolvimento setorial das atividades que compõem os segmentos da economia criativa; 2) desenvolvimento territorial estimulando a valorização das redes, dos costumes, das tradições e vocação local; 3) desenvolvimento transversal, levando componentes da economia criativa a todos os segmentos e setores da economia, de forma a gerar valor, diferenciais e estimular a competitividade das empresas (SEBRAE, 2012). O segundo eixo é o que tem catalisado boa parte das ações do SEBRAE junto aos territórios. Em razão da sua grande capilaridade, penetração nacional, competência técnica especializada e poder de mobilização, o SEBRAE reúne mais recursos e conveniências para imprimir ao seu discurso e às suas técnicas um forte acento culturalista, que concorre diretamente para fomentar negócios e empreendimentos em torno dos produtos e serviços que encarnam a diversidade e as tradições histórico-culturais dos lugares, e, assim, fazer de signos, marcas e selos - como o título de Patrimônio Cultural Imaterial e o selo de Indicação Geográfica - ativos simbólico-econômicos dos e nos territórios.

Como se pode inferir, a atuação dos agentes estatais de mercado tem sido decisiva para a conversão do território em um valioso ativo simbólico-econômico. Esses processos são recorrentes e integram uma das dinâmicas mais complexas dos mercados culturais globais. No entanto, a atuação desses agentes ocorre de modo bastante diferenciado. Se o MINC, após 2003, se tornou um agente estatal de mercado (AEM) paulatinamente, o SEBRAE já o é há bastante tempo. A novidade é que o sistema SEBRAE incorporou em seu ambiente político-institucional o empreendedorismo cultural há pouco tempo. É preciso acentuar que, durante o período de hegemonia das leis de incentivo fiscais (federais, estaduais e municipais), entre 1995 e 2003, o sistema MINC não agia como um agente estatal de mercado (AEM), porquanto não favorecia o surgimento de empresas culturais especializadas, pois eram as empresas não especializadas em cultura (PETROBRAS, Vale, Natura, BRADESCO, ITAÚ, entre tantas outras) que se beneficiavam e lançavam (e ainda laçam) mão das leis de incentivo. Mesmo que essas empresas contratassem os serviços culturais de empresas especializadas para a realização de eventos e atividades artístico-culturais, o número de 
empresas culturais propriamente ditas cresceu pouco entre 1995 e 2003. O crescimento dessa modalidade de empresas e o trabalho a elas associado, só se acentuou mesmo a partir de 2003. De acordo com o IPEA, o número de indivíduos que exerciam empregos culturais, em 2003, era de 1,5 milhões, ao passo que, em 2009, já era de 2 milhões, representando, em 6 anos, um crescimento de 33\%, o que significou uma variação líquida positiva de 432,8 mil ocupações.

É imperioso assinalar também que, tanto a expansão das empresas culturais quanto dos profissionais culturais, só ocorreu porque o consumo simbólico-cultural das famílias experimentou um crescimento significativo. Em 2003, o gasto total das famílias brasileiras com cultura representava 3\% do orçamento familiar; já em 2010 esse mesmo gasto alcançou o percentual de 5\%, quase o dobro. $\mathrm{O}$ crescimento no intervalo de oito anos representou um substancial volume de recursos gastos com bens, serviços e atividades simbólico-culturais, aproximadamente $\mathrm{R} \$ 65$ bilhões, cerca de 55\% do chamado PIB da cultura (IPEA, 2012). Por seu turno, o crescimento dos gastos culturais das famílias durante o período supracitado só foi possível em razão da expansão geral do estoque de empregos formais entre 2004 e 2014, em função da valorização real do salário mínimo e da disponibilidade de crédito. Portanto, como já assinalamos em outra oportunidade, a conversão de determinadas instituições públicas em agentes estatais de mercado (como o MINC e o BNDES), especialmente no âmbito dos mercados culturais, ocorreram mais pelas pressões e tensões estruturais, como a elevação geral do consumo, e menos pela capacidade de antever ou criar tendências. No decurso dessas pressões, é bem verdade, notadamente entre 2005 e 2014, tais instituições foram adequando seus programas, ações e projetos às novas exigências estruturais - isto é, foram se tornando, paulatinamente, agentes estatais de mercado (AEM).

Diversidade, cultura, história e natureza - as Indicações Geográficas (IGS) e a construção do valor/selo de autenticidade

As Indicações Geográficas (IGs) estão inscritas na teia jurídico-normativa dos direitos intelectuais que, após a Rodada do Uruguai (1994), criou o arcabouço legal do Acordo Relativo aos Aspectos do Direito da Propriedade Intelectual Relacionados com o Comércio (ADPIC), também conhecido internacionalmente como acordo TRIP's. No Brasil, a Indicação Geográfica ganhou forma e densidade jurídica por meio da Lei de Propriedade Industrial n. 9.279/1996, que, entre os artigos 176 e 182, dispõe sobre os usos, as formas de proteção e concessão das Indicações Geográfica (IG). No âmbito 
da supracitada legislação, a IG é tratada como uma modalidade da produção industrial, semelhante à patente e à marca industrial, trazendo, no entanto, a especificidade das marcas coletivas. De acordo com a Organização Mundial da Propriedade Intelectual, na média global de trinta países pesquisados, os registros e usos do copyright correspondem a 5,4\% do Produto Interno Bruto (PIB) global.

Figura 1- Estrutura da propriedade intelectual

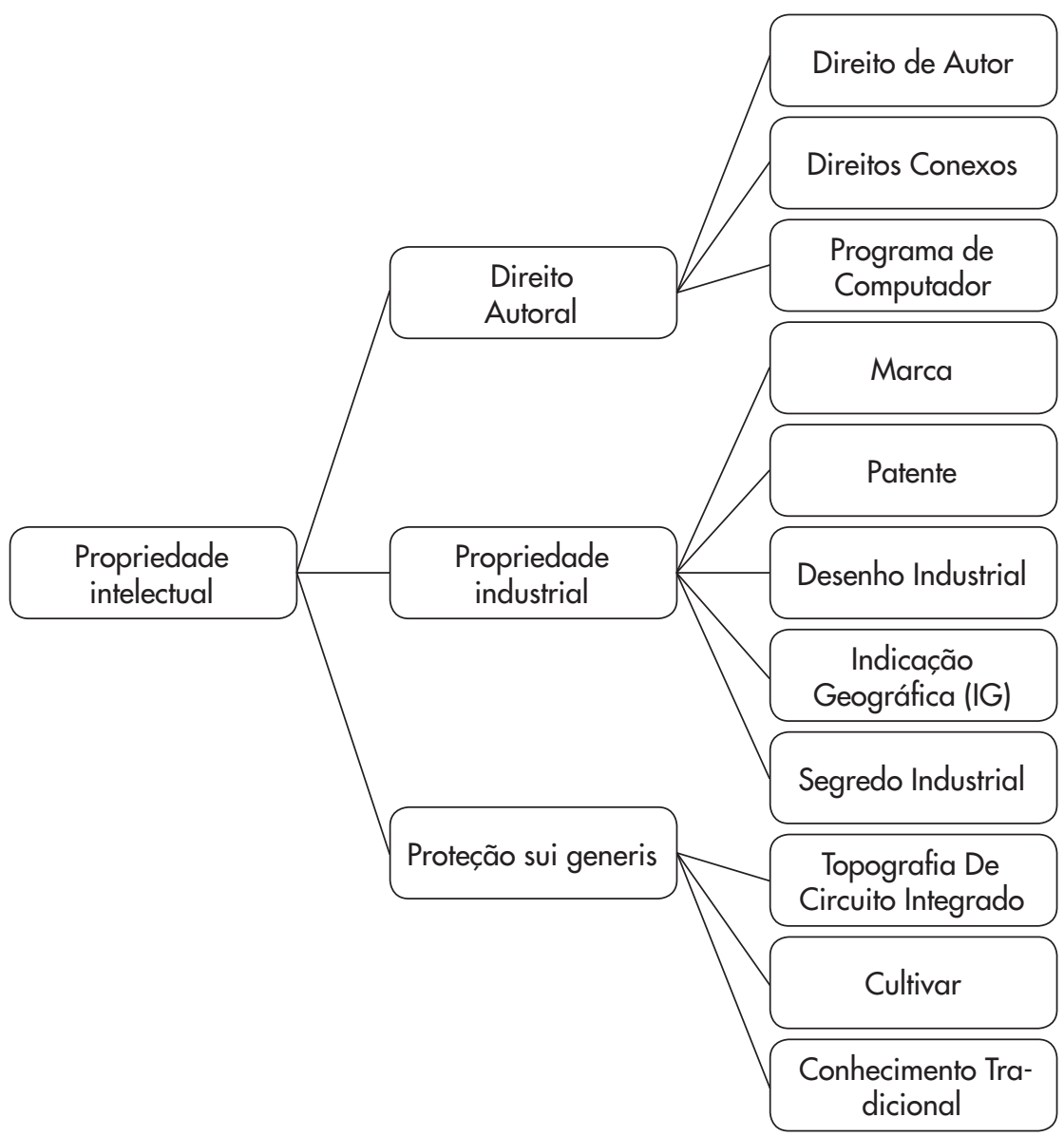

Fonte: INPI, apud SILVA, 2015.

As mudanças no regime de produção, acumulação e geração de valor no capitalismo pós-industrial têm deslocado para os setores de serviços as principais atividades econômicas e os seus respectivos processos de inovação, diferenciação e competição, que têm no registro jurídico da propriedade intelectual uma reserva permanente de ganhos financeiros. Embora concentrem 
recursos e reforcem assimetrias entre corporações, regiões, países e classes sociais, a propriedade intelectual também permite o uso dos seus dispositivos para mitigar essas mesmas assimetrias. Em 2014, o INPI, em parceria com o SEBRAE, publicou a $4^{\text {a }}$ edição do catálogo de Indicações Geográficas Brasileiras. Distribuídas ao longo de 259 páginas, o catálogo traz um alentado material informativo, um rico acervo fotográfico e iconográfico, além de aspectos conceituais, jurídicos e documentais acerca das indicações geográficas brasileiras. Escrito em português e inglês, o catálogo está dividido em duas grandes partes - indicações de procedência (IP) e denominação de origem (DO). A modalidade de Indicação de Procedência "valoriza a história e a tradição produtiva de um determinado produto, protege a relação entre o produto e a sua reputação, em razão da sua origem geográfica específica" (INPI; SEBRAE, 2014). Já a Denominação de Origem, estabelece que se trata do reconhecimento de que "uma determinada área tenha um produto cujas qualidades sofrem influência exclusiva ou essencial por causa das características daquele lugar, incluídos fatores naturais e humanos". Conforme o SEBRAE/ PNPI, "As Indicações Geográficas são ferramentas coletivas de valorização de produtos tradicionais vinculados a determinados territórios. As Indicações Geográficas devem promover os produtos e sua herança histórico-cultural, que é intransferível”.

Até o final de 2011 havia no Brasil apenas 18 IGs; no início de 2016 esse número saltou para 54. Um crescimento de $200 \%$ em quatro anos. Na Europa, onde o registro da IG remonta ao início da década de 1990, existe mais de 3000 indicações geográficas, com destaques para Espanha, França e Itália. As indicações Geográficas (IGs) potencializam as cadeias de significação e valorização simbólico-material dos territórios, irrigam de sentido as materialidades dos lugares, dotando-os de novos atributos e competências estético-naturais e histórico-culturais, promovendo e implementando as tecnologias da autenticidade, na forma de selos jurídicos e marcas públicas que chancelam a origem e procedências dos produtos. O reconhecimento e o depósito legal das indicações geográficas exige uma consistente justificativa culturalista, ancorada na demonstração de que o produto em questão possui uma densa vinculação com os processos histórico-culturais e naturais de formação dos territórios, de seus lugares e memórias. O lastro teórico dessa justificação é tomado de empréstimo da antropologia cultural e da história, que definem a cultura como uma totalidade de práticas, crenças, expressões, costumes, formas de pertencimento e identidade, códigos morais, tradições religiosas, saberes e fazeres. Essa justificativa necessita evidenciar que o produto/bem aspirante 
ao selo/reconhecimento de Indicação Geográfica (IG) é parte integrante e resultado da dimensão cultural, histórica e natural dos territórios. Subjaz a esse regime de justificação, a seguinte percepção, esposada pelo SEBRAE e o INPI - onde há território habitado, há também história, tradição e cultura, e, logo, pode haver a valorização exitosa de produtos e serviços, que poderão se tornar uma IG específica. Com efeito, todos os territórios abrigam potenciais Indicações Geográficas (IG).

Tal justificativa reforça a expectativa do fluxo de consumidores que buscam experiências e sensações "genuínas" e diferenciadas, proporcionadas, em grande medida, pela fruição da gastronomia (comidas, bebidas e iguarias), pelo uso do artesanato (roupas, joias e adornos), o consumo de produtos agroalimentares (mel, carnes, vinhos, queijos, café, etc.) e pelo manuseio de artefatos e objetos consagrados com o selo de Indicação Geográfica. A justificativa culturalista preenche, direta ou indiretamente, a demanda pelo consumo do "autêntico", do "singular" e do "genuíno". Cotejando a experiência da IG na Europa e no Brasil, Froehlich e Dullius assinalam: "Esta forma de reconhecimento permitiu a valorização dos atributos locais específicos; buscam associar, no imaginário do consumidor, as relações de produção com a cultura e a tradição, tipicidade e qualidade" (Froehlich e Dullius, 2012: 21). Desse modo, a rede de proteção legal, valorização governamental, empresarial, comunitária, associativa e estatal que se tece com vistas à obtenção do selo/marca da IG é motivada também (e, em alguns casos, principalmente) para atender demanda por bens que traduzam a totalidade histórico-cultural-natural dos territórios e seus lugares.

\section{- Artesanato, moda e valor: a IG do bordado Filé de Alagoas.}

As IGs brasileiras estão divididas em 5 grupos: a) bebidas (vinhos, cajuína, espumantes, café, aguardentes e cachaças), com 20 registros; b) produtos agroalimentares (carnes, queijos, doces, mel, presunto, linguiça e arroz...), que contam com 11 registros; c) frutas, vegetais e animais (melão, uva, cacau, algodão colorido, extratos de própolis, camarão, peixes e açafrão), que contam com 6 registros; d) produtos semi-industrialzados (calçados, couro, biscoitos e serviços tecnológicos), que contam com 5 indicações; e) artesanato (bordados, joias e design de pedras), que contam com 13 indicações. Salta aos olhos o caso do artesanato, que, de apenas 2 indicações, em 2011, passou a contar com 13 indicações, em 2016, entre o artesanato de joias, pedras, bordados e rendas. As atividades e serviços artesanais são aquelas com 
maior capilaridade no território brasileiro entre os setores criativos. Essa presença, no entanto, não é homogênea. Entre 2006 e 2014, ocorreu uma redução no artesanato de tapeçaria, couro, barro e madeira; ao passo que os artesanatos de tecelagem, material reciclável e vidro lograram crescimento. $\mathrm{O}$ destaque cabe, contudo, ao artesanato de bordado e à culinária típica. $\mathrm{O}$ primeiro está presente em $76,2 \%$ dos municípios brasileiros (esse percentual era de 75,4\% em 2006); já a culinária típica saltou de 18,1\%, em 2006, para $30,3 \%$, em 2014. Um e outro cresceram no mesmo movimento de expansão dos programas voltados ao turismo cultural no âmbito dos estados e municípios, notadamente no que diz respeito ao crescimento dos festivais de gastronomia e das feiras de artesanato.

No Brasil, o Estado de Alagoas é um dos que mais tem se destacado nas modalidades do chamado artesanato tradicional, especialmente o artesanato de bordados, rendas, fios e culinária típica. O território alagoano tem sido concebido pelos principais agentes político-institucionais do Estado como o território por excelência do artesanato tradicional e de referência cultural. Em abril de 2016, o INPI concedeu o registro de Indicação de Procedência (IP) para o bordado Filé, de Alagoas, tornando-se assim uma IG específica, referida aos limites do Complexo Territorial Estuarino Lagunar Munadú-Manguaba (território das Lagoas Mundaú-Manguaba - CTELMM), abarcando os municípios nos quais o ofício do bordado Filé foi catalogado e cultivado pelas comunidades locais: Maceió (Bairro do Pontal da Barra), Marechal Deodoro, Santa Luzia do Norte, Coqueiro Seco, Pilar, Satuba e Rio Largo. O bordado Filé reúne aspectos na sua composição (multiplicidade de combinação de pontos e cores, rigoroso acabamento manual e design sinuoso e vibrante) que tem atraído consumidores e mobilizado as energias criativas de muitas artesãs.

Alagoas é o Estado brasileiro que possui o maior número de artesãos e artesãs cadastrados junto ao Programa do Artesanato Brasileiro (PAB), criado em 2013 e coordenado pela Secretaria da Micro e Pequena Empresa, vinculada à Presidência da República (SMPE/PR). Do total de artesãos no Estado, $86 \%$ são mulheres, $92 \%$ têm casa própria e a grande maioria $(87 \%)$ contribuem para a previdência social, mediante recolhimento assegurado pela Carteira do Artesão, documento expedido pelo PAB/AL. A maioria dos artesãos $(67 \%)$ dedica de 4 a 5 horas diária para as atividades artesanais, sendo que $91 \%$ do total de trabalhadores criativos do artesanato alagoano utilizam a própria casa como oficina e, muitas vezes, também como local de venda e comercialização. Do total cadastrado, $86 \%$ apontam o artesanato como a 
sua atividade principal e como a mais importante fonte da renda familiar. Segundo o Ministério do Desenvolvimento, Indústria e Comércio (MDIC), em 2008, o Brasil possuía 8,5 milhões de artesãos, que movimentavam anualmente um volume financeiro de $\mathrm{R} \$ 28$ bilhões, próximo a segmentos industriais, como o setor automobilístico.

Em 2014 o bordado Filé foi registrado como Patrimônio Cultural Imaterial do Estado de Alagoas junto ao Conselho de Cultura do Estado. Na ocasião, a gerente da Unidade de Turismo e Economia Criativa do SEBRAE-AL, Vanessa Fagá, declarou que "esse reconhecimento do Conselho de Cultura do Estado representa um passo importantíssimo para cada artesã que produz o Bordado Filé. É o registro de um patrimônio que vem sendo feito com dedicação, arte e criatividade há gerações" (Gazetaweb, 2015). Também tramita no Instituto do Patrimônio Histórico e Artístico Nacional (IPHAN) a solicitação de registro do bordado Filé como patrimônio imaterial da cultura brasileira, inscrito no livro de fazeres. Em muitos casos, a obtenção do registro/título de patrimônio cultural imaterial estadual se tornou uma condição, parte de um protocolo maior para a obtenção/conquista da IG. Junto a essas ações foi concluída a realização da justificativa sócio-histórica e cultural acerca das evidências de singularidade do bordado Filé na região das lagoas, conduzida pelos pesquisadores da Universidade Federal de Alagoas (UFAL). Também nessa direção, foi concluído o estudo de delimitação geográfica da região de ocorrência do Bordado Filé, levado a cabo pela equipe de estudos de georreferenciamento da UFAL. Seguindo esse diapasão, foi criado o Instituto Bordado Filé (nome da associação de filezeiras e filezeiros), que será o depositário dos direitos intelectuais coletivos do selo da Indicação Geográfica (IG). Em 20150 Instituto Bordado Filé, em parceria com o SEBRAE-AL e a Prefeitura Municipal de Maceió, lançou o Caderno de Instruções do Filé, que traz informações acerca do processo histórico-criativo de consecução do Filé. De acordo com Vânia Amorim, assessora da SEPLAND-AL, a expectativa é que a conquista da IG resulte em um aumento de cerca de $30 \%$ nas vendas dos artesãos e artesãs dedicados (as) ao Filé. Como ressalta Sônia Normande, coordenadora do Programa do Artesanato Brasileiro (PAB) em Alagoas: “o Filé alagoano terá valor superior aos que não apresentam origem definida e os compradores têm a segurança de adquirir um produto que tem tradição e qualidade comprovadas" (SEPLANDE-AL). 


\begin{tabular}{|c|c|c|}
\hline AGENTES & ESFERA DE AÇÃO & $\begin{array}{l}\text { NATUREZA } \\
\text { INSTITUCIONAL }\end{array}$ \\
\hline \multirow{8}{*}{ SEBRAE-AL } & Processo de IG do bordado Filé & \multirow{8}{*}{ Entidade Paraestatal } \\
\hline & Articulação dos Arranjos Produtivos Locais (APLs) & \\
\hline & Capacitações & \\
\hline & Unidade de Turismo e Economia Criativa (UTEC) & \\
\hline & Lançamento do Termo de Referência da Economia Criativa & \\
\hline & $\begin{array}{l}\text { Pesquisa sobre Desenvolvimento Territorial Sustentável } \\
\text { no Pontal da Barra }\end{array}$ & \\
\hline & Incentivo à formalização & \\
\hline & Formação de Microempreendedores Individuais & \\
\hline \multirow{8}{*}{ SEDETUR-AL } & Processo de IG do bordado Filé & \multirow{8}{*}{$\begin{array}{l}\text { Órgão Público do } \\
\text { executivo estadual }\end{array}$} \\
\hline & Diretoria de Design e Artesanato & \\
\hline & Diretoria dos Arranjos Produtivos Locais & \\
\hline & \begin{tabular}{|l|} 
Diretoria de Micro e Pequenos Negócios \\
\end{tabular} & \\
\hline & Superintendência de Desenvolvimento Regional & \\
\hline & Coordenação do PAB em Alagoas & \\
\hline & Inserção dos Artesãos em Feiras e Eventos & \\
\hline & $\begin{array}{l}\text { Concessão da Carteira Nacional do Artesão e Carteira } \\
\text { Nacional do Trabalhador Manual }\end{array}$ & \\
\hline \multirow{3}{*}{ UFAL } & Processo de IG do bordado Filé & \multirow{3}{*}{$\begin{array}{c}\text { Universidade } \\
\text { Federal de Alagoas. } \\
\text { Autarquia federal. }\end{array}$} \\
\hline & Mapeamento da ocorrência do bordado Filé no CELMM & \\
\hline & Pesquisa sobre a origem e a atividade do Filé no CELMM & \\
\hline \multirow[b]{2}{*}{ SECULT-AL } & Conselho Estadual de Cultura & \multirow{2}{*}{$\begin{array}{c}\text { Órgão Público do } \\
\text { poder executivo } \\
\text { estadual }\end{array}$} \\
\hline & Política de Patrimônio Cultural Imaterial & \\
\hline FMAC & $\begin{array}{l}\text { Engajamento na construção da sede do Instituto do } \\
\text { Bordado Filé }\end{array}$ & $\begin{array}{c}\text { Órgão Público do } \\
\text { poder executivo } \\
\text { municipal (Maceió) }\end{array}$ \\
\hline SEMPTUR & $\begin{array}{l}\text { Divulgação turística do bordado Filé e do bairro do Pon- } \\
\text { tal da Barra - Maceió }\end{array}$ & $\begin{array}{c}\text { Órgão Público do } \\
\text { poder executivo } \\
\text { estadual }\end{array}$ \\
\hline \multirow{5}{*}{ BRASKEM } & $\begin{array}{l}\text { Possível parceria na construção da sede do Instituto } \\
\text { Bordado Filé }\end{array}$ & \multirow{5}{*}{ Empresa Privada } \\
\hline & Manutenção do Cinturão Verde & \\
\hline & Projeto Lagoa Viva & \\
\hline & $\begin{array}{l}\text { Construção e manutenção da Área de Esporte, Lazer, } \\
\text { Eventos do bairro do Pontal da Barra - Maceió }\end{array}$ & \\
\hline & $\begin{array}{l}\text { Construção do Pórtico de Entrada do Pontal da Barra } \\
\text { (Maceió) }\end{array}$ & \\
\hline AMA & Principal evento de divulgação do artesanato em Alagoas & $\begin{array}{c}\text { Associação de pre- } \\
\text { feituras do Estado } \\
\text { de Alagoas }\end{array}$ \\
\hline \multirow{2}{*}{$\begin{array}{l}\text { INSTITUTO } \\
\text { DO BORDA- } \\
\text { DO FILÉ }\end{array}$} & Fomento da atividade artesanal do Filé no CELMM & \multirow{2}{*}{$\begin{array}{l}\text { Associação de arte- } \\
\text { sãs e artesãos }\end{array}$} \\
\hline & Beneficiamento dos municípios do CELMM & \\
\hline
\end{tabular}

Fonte: Silva, 2015. 
A Tabela 1 evidencia as interfaces políticas, técnicas e institucionais da rede montada para a obtenção/conquista da indicação geográfica do bordado Filé de Alagoas. No interior dessa rede há disputas políticas, controles, usos, agenciamentos e uma evidente divisão do trabalho técnico-político. Nessa rede se inscrevem relevantes agentes estatais de mercado, como o SEBRAE-AL e a Secretaria de Turismo de Alagoas (SEDETUR). Por meio da construção político-institucionais de redes como essa se constata como são frágeis as supostas polaridades empíricas entre os interesses dos órgãos estatais (sobretudo da administração direta, vinculados ao poder executivo) e os interesses das organizações privadas. Mercado e Estado compõem um amálgama, composto por um complexo e assimétrico feixe de interdependências socioeconômicas (Elias, 1997). Em muitos casos, como no reconhecimento e nos diversos usos da IG, os principais agentes estatais de mercado (SEBRAE e INPI) são também os principais responsáveis pela construção socioeconômica de mercados bem específicos. Essa sustentação retira parte de sua força da assertiva cunhada por Bourdieu por ocasião da sua pesquisa sobre o mercado da casa própria na França: "é uma das funções do Estado construir mercados" (Bourdieu, 2001). Mesmo em um Estado com baixa capacidade de mobilização de recursos políticos, institucionais e simbólicos, com pouca densidade empresarial e assolado pelos piores índices de desenvolvimento humano do país, além de uma desigualdade socioeconômica atroz, como é o caso de Alagoas, os interesses de parcela dos agentes estatais de mercado (AEM) e dos agentes privados de mercado (APM) se cruzam e se acomodam.

A simples notícia do processo de solicitação de registro do bordado Filé vicejou na imprensa local e nacional matérias e reportagens a respeito. Na Revista Brasil Almanaque de Cultura Popular, n. 174, de outubro de 2013, distribuída gratuitamente pela Companhia Aérea TAM, figura uma reportagem acerca das rendas e bordados nordestinos. Intitulada Design popular brasileiro, a reportagem traz informações e imagens sobre a Renda Irlandesa de Divina Pastora, a Renda Renascença do Cariri Paraibano (ambas reconhecidas como Indicações Geográficas) e o bordado Filé de Alagoas e do Ceará. Na fotografia que exibe o Bordado Filé na supracitada revista, a legenda diz apenas que esse artesanato pode ser encontrado nos Estados de Alagoas e Ceará. Na imagem do Filé apresentada na referida revista, notamos que ela exibe o trançado, a trama e as combinações de cores e texturas que têm notabilizado o Filé alagoano. Esse aspecto evidencia que, no âmbito da imprensa escrita e de parte do segmento editorial brasileiro, há uma indistinção envolvendo o Bordado Filé alagoano e o Filé cearense. No entanto, no maior acervo digital icônico do planeta (o portal Google 
Imagem), uma vez digitada a expressão "Filé alagoano", tem-se acesso a uma plêiade de imagens de peças (vestidos, toalhas, colchas, camisetas, batas etc.), recobertas pelo bordado alagoano; ao passo que, feito o mesmo procedimento para o filé cearense, não se vê na tela qualquer imagem de artesanato. Este exemplo atesta a projeção e visibilidade que o Filé alagoano tem experimentado, confirmando a pujança do processo recente de valorização simbólico-material do artesanato alagoano e as suas interfaces com as políticas culturais de empreendedorismo cultural e desenvolvimento local.

A publicação intitulada Economia da Cultura e da moda no Brasil: um estudo para políticas públicas (2012), realizada pelo Conselho Nacional de Políticas Culturais (CNPC/MINC), aponta como as principais forças e potencialidades da moda brasileira: "o valor cultural local e a detenção dos saberes tradicionais". Como primeira diretriz para a adoção das políticas culturais para a moda, o documento traz a seguinte proposta: "reconhecer e promover a moda como bem cultural e patrimônio nacional, considerando a sua diversidade e os seus repertórios" (CNPC, 2012). O Brasil foi o país que apresentou o maior crescimento percentual no mercado global da moda. Durante esse período, as empresas do setor aumentaram o seu faturamento em $400 \%$, alcançando $\mathrm{R} \$ 140$ bilhões. Nesse mesmo período, o Brasil saiu da $14^{\mathrm{a}}$ colocação global para a $8^{\mathrm{a}}$ posição entre os maiores mercados mundiais (Exame, 2013). No caderno de economia do Jornal Gazeta de Alagoas (jornal de maior circulação no Estado), do dia 25 de agosto de 2013, na primeira página interna do suplemento, foi publicada uma longa matéria, coalhada de fotografias e imagens de modelos desfilando e exibindo as criações da parceria da marca Cantão com as artesãs do Filé alagoano. Trata-se de um exemplo da ampla cobertura dispensada a um dos principais eventos de moda do Nordeste, o Alagoas Trend House, que fez correr para a capital alagoana diversos estilistas, produtores e muitos executivos das principais marcas nacionais. De acordo com a matéria citada, um dos instantes mais emocionantes do evento foi a homenagem prestada a algumas das artesãs que confeccionaram o bordado Filé especialmente para os cortes e modelos criados pelas estilistas da Cantão.

Durante o evento em Maceió, a grife Cantão apresentou para o público a nova coleção, intitulada 4 Cantos, cujo grande destaque coube às peças que recebem aplicação do bordado Filé, sendo 15 criações no total. Estiveram presentes ao desfile trinta das mais de duzentas artesãs que trabalharam e contribuíram diretamente para a criação e adequação do bordado às peças mencionadas. À medida que as modelos desfilavam com as criações, um vídeo exibia o modo específico de se tramar o Filé e os usos nas peças em exposição no corpo da 
modelo. Na mesma edição do referido jornal, o Caderno Maré (revista de arte e cultura do suplemento) trouxe uma longa matéria de capa sobre a singularidade da moda alagoana, cujo traço distintivo é conferido pela interface com o artesanato local, especialmente o Filé, que aparece cobrindo o corpo das modelos que se apresentaram no Alagoas Trend House.

O interesse da marca Cantão pelo bordado Filé iniciou-se em fevereiro de 2013. Após tomar contato com o bordado, mediante uma publicação local (Mestres Artesãos), enviado por uma franquiada da marca em Maceió, a estilista Lanza Mazza (coordenadora de etilo da Cantão), iniciou uma pesquisa no bairro do Pontal da Barra (Maceió) e no município de Marechal Deodoro. Após a pesquisa, a equipe de criação da grife carioca iniciou o processo de divisão de tarefas, encomenda das criações e o processo criativo de preparação e escolha dos designs que seriam aplicados nas peças e modelos. Para tanto, foram contratadas mais de 200 artesãs do perímetro compreendido pelo complexo estuarino Mundaú-Manguaba, mediante uma parceria que envolveu as cooperativas locais, o SEBRAE-AL e a Secretaria de Turismo de Maceió. O resultado chegou às lojas de todo país em novembro de 2013, como consequência da pesquisa realizada entre fevereiro e março do mesmo ano e do apoio dados pelos executivos da marca, que julgaram a ideia bastante apropriada e fiel à proposta da grife: "eles ficaram empolgados porque a Cantão é uma marca genuinamente brasileira, que valoriza a expressão cultural do nosso povo" (Gazeta de Alagoas, 25/08/2013). Ainda segundo a coordenadora de criação da Cantão, a coleção traz, em todas as suas peças, uma tag (etiqueta) especial, descrevendo o processo do Filé e contendo o nome da artesã que confeccionou o bordado aplicado na peça, "são peças muito especiais, requer uma atenção maior. A tag faz a gente conseguir esse ciclo todo que envolve costureira, bordadeira, até a cliente final, que vai saber o nome dessa artesã” (Gazeta de Alagoas, 25/08/2013).

A coleção 4 Cantos do Mundo, que tem o Filé alagoano como a principal nuance estético-criativa, foi distribuída em mais de 50 lojas da marca e cerca de 1100 multimarcas associadas, presentes no Brasil e no exterior. Desde os anos de 1970, a marca se posicionou no ascendente mercado brasileiro como uma tendência que buscava imprimir sutileza e despojamento a um público feminino dinâmico, singelo e contestador, cunhando o lema Flower Power (poder da flor). A partir da década de 1990, a marca se destaca no varejo especializado brasileiro, abarcando um conjunto de produtos (mochilas, tênis etc.), mas, sobretudo, assumindo a liderança na venda de vestidos e batas. No endereço eletrônico da marca se lê: "mulher que veste a marca tem personalidade marcante, é espontânea e autêntica, prefere revelar de forma natural e despojada a 
sua sensualidade. Sem ser refém dos clichês da moda” (Cantão, 2017). A Cantão possui um dos melhores posicionamentos mercadológicos entre as marcas que se dedicam ao público feminino entre 18 e 35 anos, notadamente entre os estratos de classe média e média alta. De acordo com as consultorias especializadas, o capital financeiro para a instalação da loja franquiada varia entre $\mathrm{R} \$ 90$ e 230 mil, sedo a taxa de franquia de $\mathrm{R} \$ 35$ mil. O uso do artesanato sinaliza o modo como a Cantão negocia e consolida a sua imagem de marca jovem, comprometida com valores, como diversidade cultural, sustentabilidade ambiental e a valorização das expressões artesanais, ao mesmo tempo em que está comprometida com a inovação de produtos, cujo acabamento e a natureza dos detalhes são fundamentais para a afirmação de um estilo corporativo-imagético.

O repertório criativo do chamado artesanato cultural e tradicional (SEBRAE, 2011) tem emprestado legitimidade estética e dignidade cultural às campanhas contemporâneas das grandes marcas da moda brasileira. Certamente, se a indicação geográfica do bordado Filé alagoano, do território Mundau-Manguaba, já estivesse oficializada quando do lançamento da coleção 4 Cantos, da marca Cantão, os ganhos materiais para as detentoras dos direitos (artesãs e artesãos) seriam bem maiores. Com efeito, fica patente que, assim como no caso do registro do patrimônio imaterial e também com a IG, se instaura um sistema de usos e contra usos recíprocos que envolvem não só os detentores imediatos dos direitos e títulos (comunidades, criadores, portadores de saberes e fazeres, sindicatos, associações, cooperativas etc.), mas uma série variada de agentes situados nos territórios e fora deles: empresas, marcas, corporações transacionais, governos, órgãos estatais e consumidores - locais e globais.

\section{Considerações finais}

Os interesses e os investimentos simbólico-materiais sobre o território têm se renovado. Localiza-se e defende-se uma potencialidade que escapa, na contemporaneidade, aos domínios convencionais da agropecuária e do agronegócio. A consecução do valor das mercadorias, serviços e produtos passa, cada vez mais, pela dimensão simbólico-cultural dos territórios e suas identidades locais e menos pela dimensão propriamente física do espaço. Para a construção do valor econômico, importa muito mais a tessitura de uma narrativa de pertencimento histórico-cultural, escorada na valorização dos saberes/fazeres locais, secundada em categorias-força-prestígio, como as de diversidade cultural, patrimônio imaterial, identidade, tradição e autenticidade, que emprestam legitimidade a novos produtos e artefatos, borrando os limites entre a dimensão 
física e simbólica dos territórios. Como corolário, a busca por reconhecimento jurídico, singularidade e autenticidade histórico-cultural têm desencadeado novos mecanismos de competição econômica, especialização técnica e tensão política entre os territórios e seus lugares, resultado do processo de culturalização e turistificação dos territórios.

\section{Referências}

BAUMAN, Zygmunt. Vida para consumo. Rio de Janeiro, Jorge Zahar, 2008.

BOURDIEU, Pierre. As estruturas sociais da economia. Lisboa, Instituto Pieget, 2001.

CANCLINI, Nestor Garcia. A sociedade sem relato. São Paulo, Edusp, 2013.

ELIAS, Norbert. Os alemães. Rio de Janeiro, Jorge Zahar, 1997.

FOUCAULT, Michael. Arqueologia do saber, Rio de Janeiro, Forense, 1988.

FROEHLICH, José Marcos; DULLIUS, Paulo Roberto. As experiências de indicações geográficas no Brasil, in FROEHLICH e DULLIUS (orgs.), Desenvolvimento territorial: produção, identidade e consumo. Porto Alegre, UFRGS, 2012, pp. 21-46.

IBGE - Instituto Brasileiro de Geografia e Estatística. Pesquisa de informações básicas estaduais. Pesquisa de informações básicas municipais. Brasília, 2014.

INPI - Instituto Nacional de Propriedade Industrial; SEBRAE - Serviço Brasileiro de Apoio às Micro e Pequena Empresa. Indicações Geográficas brasileiras. Catalogo Nacional de Indicações Geográficas. Brasília, 2014.

IPEA - Istituto de Pesquisa Econômica Aplicada. Disponível em: <http://www.ipea.gov. br/portal/> . Acesso em: 11 abr. 2013.

IPHAN - Instituto do Patrimônio Histórico e Artístico Nacional. Disponível em: <http:// portal.iphan.gov.br/>. Acesso em: 22 ago. 2016.

JORNAL Gazeta de Alagoas. Caderno de Economia, ed. 25 ago. 2013.

. Caderno Mare. Disponível em: <http://gazetaweb.globo.com/portal/>. Acesso em: 16 nov. 2014 .

LIPOVETSKY, Gilles ; SERROY, Jean. A estetização do mundo: viver na era do capitalismo artista. São Pulo: Cia das Letras, 2015.

MDIC - Ministério da Indústria, Comércio Exterior e Serviços. Disponível em: <http:// www.mdic.gov.br/>. Acesso em: 25 maio 2014.

MINC - Ministério da Cultura. Plano da Secretaria da Economia Criativa. Brasília, 2011. . Disponível em: <http://www.cultura.gov.br>. Acesso em: 23 jun. 2016.

. Economia da Cultura e da moda no Brasil: um estudo para políticas públicas, realizada pelo Conselho Nacional de Políticas Culturais (CNPC/MINC). Brasília, 2012. ORTIZ, Renato. Universalismo e diversidade. São Paulo, Boitempo, 2015. 
PNDR - Política Nacional de Desenvolvimento Regional. Ministério da Integração Nacional. Brasília, 2011.

REVISTA Brasil Almanaque de Cultura Popular, n. 174, outubro 2013.

SEBRAE. Termo de referência, atuação do sistema SEBRAE na economia criativa. Brasília, 2012. . Música tocando negócios: um guia para ajudar a você empreender na música. Brasília, 2015. . Termo de Referência - Atuação do Sistema SEBRAE na Economia Criativa. Brasília, 2012.

SEPLANDE - Secretaria de Planejamento e Desenvolvimento Econômico. Disponível em; <http://www.seplande.al.gov.br/>. Acesso em: 14 jun. 2014.

SILVA, Bruno Gabriel Passos. Entre tramas e rendas: a construção de uma agenda política para o artesanato e a economia criativa em Alagoas. 2015. Dissertação (Mestrado em Mestrado em sociologia) - Universidade Federal de Alagoas (UFAL). TAYLOR, Charles. A ética da autenticidade. São Paulo, Realização Editora, 2011.

UNESCO. Convenção para Salvaguarda do Patrimônio Cultural Imateriais. Paris, 2003. . Convenção Sobre a Proteção e a Promoção da Diversidade das Expressões Culturais. Paris, 2005.

URRY, John. O olhar do turista: lazer e viagens nas sociedades contemporâneas. São Paulo, Editora Studio Nobel/SESC, 1996.

YUDICE, Georg. A conveniência da cultura: usos da cultura na era global. Belo Horizonte, UFMG, 2004.

Recebido em 25/11/2016

Aprovado em 20/12/2016

\section{Como citar este artigo:}

ALVES, Elder P. Maia. Diversidade cultural, território e tradição: a nova agenda do desenvolvimento local no Brasil. Contemporânea - Revista de Sociologia da UFSCar, v. 7, n. 1, jan.- jun. 2017, pp. 91-117. 